\title{
Optimal monetary policy reaction function in a model with target zones and asymmetric preferences for South Africa
}

\author{
Ruthira Naraidoo a,*, Leroi Raputsoane ${ }^{\mathrm{b}, 1}$ \\ a University of Pretoria, Department of Economics, Pretoria, 0002, South Africa \\ ${ }^{\mathrm{b}}$ Research Department, South African Reserve Bank, Pretoria, 0001, South Africa
}

\section{A R T I C L E I N F O}

Article history:

Accepted 13 September 2010

Available online $\mathrm{xxxx}$

JEL Classification:

C51

C52

E52

E58

Keywords:

Monetary policy preferences

Target zones

Asymmetries

\begin{abstract}
A B S T R A C T
This paper estimates the optimal response of the SARB to deviations of inflation and output from their target values over the inflation targeting era. This is achieved using an empirical framework that allows the central bank's policy preferences to be zone-like and asymmetric. The first major finding is that the monetary authorities' response towards inflation is zone symmetric. That is, they react in a passive manner when inflation is within the target band whereas they become increasingly aggressive when it deviates from the target band. The monetary authorities also react with the same level of aggressiveness regardless of whether inflation overshoots or undershoots the inflation target band. The second major finding is that the monetary authorities' response to output fluctuations is asymmetric. That is, they react more aggressively to negative deviations of output from the potential so that they weigh business cycle recessions more than expansions.
\end{abstract}

(c) 2010 Elsevier B.V. All rights reserved.

\section{Introduction}

Policy makers around the world have sought to improve transparency and accountability of their policy objectives by specifying explicit targets for variables such as inflation and output. An important development in the recent past has been the adoption of the inflation targeting framework by a growing number of developed and developing countries (Mishkin and Schmidt-Hebbel, 2001). Under this framework, monetary policy authorities make public announcements of the target inflation rate and use of interest rates to steer actual inflation towards the target with the objective of achieving price stability. This monetary policy framework is characterised by point targeting, which permits inflation to fluctuate by some margin around the specified target. Other central banks, including the South African Reserve Bank (SARB), have adopted a zone targeting monetary policy framework that allows some toleration to the fluctuation of inflation within a specified target range.

When the monetary authorities are endowed with inflation and output stabilisation, they may have an inflation bias when inflation overshoots the target and an output bias during productivity

\footnotetext{
* Corresponding author. Tel.: +27 12420 3729; fax: +27 123625207.

E-mail addresses: ruthira.naraidoo@up.ac.za (R. Naraidoo),

leroi.raputsoane@resbank.co.za (L. Raputsoane).

1 Tel.: +27 12313 3273; fax: +27 123133925 .
}

declines (Orphanides and Wilcox, 2002). Thus the monetary authorities may behave in ways that reflect asymmetries when confronted by numerous competing objectives. This implies that their responses to inflation and output may be different depending on whether these variables undershoot or overshoot their target values. The monetary authorities may also exhibit zone-like behaviours by penalising more when inflation moves out of the target range and being passive when it is within the target range. Thus an empirical framework that allows for target zones and asymmetries in monetary policy preferences is more relevant to evaluate the monetary authorities' actual practice of monetary policy setting. However, as argued by Orphanides and Wieland (2000), the quantitative evaluations of monetary policy that are based on linear models that use the Taylor (1993) rule and its extensions by Clarida et al. (2000) may not fully capture the actual practice of inflation targeting.

Empirical work on the analysis of monetary policy is dominated by studies that use the linear Taylor rule with relatively few studies that have estimated asymmetric monetary policy reaction functions. Cukierman and Gerlach (2003), Ruge-Murcia (2003), Dolado et al. (2004, 2005), and Surico (2007a,b) have shown evidence supporting asymmetries by adopting a monetary policy reaction function that feature asymmetries in either inflation or the output gap for the US, UK, EU and OECD countries. Boinet and Martin (2008) also implemented a monetary policy reaction function that feature asymmetries and zone-like behaviours for the UK and found the evidence of zone-like responses to inflation. 
This paper estimates the monetary authorities' response to deviations of inflation and output from their target values using an empirical framework which allows central bank's policy preferences to be zone-like and asymmetric. Of particular interest is whether the monetary authorities' preferences are such that they react differently to deviations in inflation and output when they overshoot or are below their target values and/or when inflation is within or outside the target range. The modelling strategy is an adaptation of the New Keynesian framework, which is the intertemporal optimisation problem where the central bank minimises a loss function subject to the constraints given by the structure of the economy. The study is important in that it allows the evaluation of the SARB's monetary policy outcomes using an analytical framework that captures the authentic inflation target band monetary policy practice under which the SARB operates. The attempt to model South Africa's monetary policy using an optimal monetary policy reaction function with zonelike and asymmetric preferences is the first to our knowledge. This monetary policy reaction function is in line with the actual practice of inflation zone targeting by the SARB where the inflation target is 3 to $6 \%{ }^{2}$

The paper is organised as follows. The next section details the theoretical model where the optimal monetary policy rule is derived from the monetary authorities' optimisation problem. Section 3 discusses the data. In Section 4, the optimal monetary policy rule is estimated and the results are reported and discussed. Section 5 concludes.

\section{Theoretical model}

The central bank's monetary policy design problem is a targeting rule following Svensson (1999) and draws from Boinet and Martin (2008). The monetary policy reaction function is an adaptation of the New Keynesian setup that is modelled as an intertemporal optimisation problem where the central bank is assumed to use all available information available at any point in time to bring the target variables in line with their desired values.

\subsection{Central bank's preferences}

The central bank sets the interest rate at the beginning of period $t$ based on the information, which is available at the end of period $t-1$. The following timing mechanism captures this intertemporal criterion as in Clarida et al. (1999):

$\operatorname{Min}_{\left\{i_{t}\right\}} E_{t-1} \sum_{\tau=0}^{\infty} \delta^{\tau} L_{t+\tau}$

where $\delta$ and $L$ is the discount factor and the period loss function, respectively.

The period loss function is a linex specification and was first introduced in the monetary policy literature by Nobay and Peel (2003). It departs from the conventional quadratic specification in that the central bank is allowed to treat differently the positive and negative deviations of inflation and output from their targets. The central bank is also indifferent between inflation rates and output within these target zones as in Boinet and Martin (2008). It extends on Surico $(2007 a, b)$ in that the linex specification is general because it approximates a number of different functions. The range of values for the rate of inflation for which the loss function is constant forms the

\footnotetext{
2 The only piece of work that have attempted estimating nonlinear monetary policy rule in the context of South Africa is Naraidoo and Gupta (2008) who make use of a smooth transition model with a quadratic logistic function to capture inflation zone targeting practice. However the approach taken in the present paper is different as the analysis is based on the optimal monetary policy rule.
}

target zone for inflation. The period loss function is specified as follows:

$$
\begin{aligned}
L_{t}= & \frac{e^{\alpha_{\pi}\left(\pi-\pi^{*}\right)^{\beta_{\pi}}}-\alpha_{\pi}\left(\pi_{t}-\pi^{*}\right)^{\beta_{\pi}}-1}{\beta_{\pi} \alpha_{\pi}^{2}} \\
& +\lambda\left(\frac{e^{\alpha_{y}\left(y_{t}\right)^{\beta_{y}}}-\alpha_{y}\left(y_{t}\right)^{\beta_{y}}-1}{\beta_{y} \alpha_{y}^{2}}\right)+\frac{\mu}{2}\left(i-i^{*}\right)^{2}
\end{aligned}
$$

where $\alpha_{\pi}$ and $\alpha_{y}$ capture the asymmetries, while $\beta_{\pi}$ and $\beta_{y}$ capture the zone-like properties in the central bank's preferences. $i^{*}$ is the desired level of interest rate, while $\pi^{*}$ is the inflation target. $\lambda>0$ is a coefficient that measures the central bank's aversion to output level fluctuation relative to the potential level, while $\mu>0$ is a coefficient that measures the central bank's aversion to interest rate fluctuations around the desired level. The policy preference towards inflation stability is normalised to 1 so that $\lambda$ and $\mu$ are expressed in relative terms.

The loss function embodies numerous characteristics of linearities, asymmetries and zone-like central bank's preferences depending on the values of $\alpha_{\pi}, \alpha_{y}, \beta_{\pi}$ and $\beta_{y}$. As special cases, whenever $\beta_{\pi}$ and $\beta_{y}$ approach one, the period loss function generalises to a linex function. Applying L'Hopital's rule on the loss function allowing $\alpha_{\pi}$ and $\alpha_{y}$ approach zero and $\beta_{\pi}$ and $\beta_{y}$ approach one simultaneously achieves a quadratic loss function. Fig. 1 illustrates the monetary authorities' preferences assuming that the central bank is more concerned about inflation overshooting its target and output undershooting its potential. Under these assumptions, high inflation relative to the target is more costly to the monetary authorities than low inflation. On the other hand, low output relative to the potential is weighted more severely than higher output.

As illustrated in Fig. 1(a) and (b), when $\alpha_{\pi}$ and $\alpha_{y}$ approach zero, the loss function is symmetric so that the deviations of inflation from its target and output from its potential are weighted equally by the monetary authorities. The loss function exhibits zone-like properties when $\beta_{\pi}$ and $\beta_{y}$ are greater than one. Given a positive value of $\alpha_{\pi}$, whenever $\pi_{t}$ is greater than zero, the linear component of the loss function is dominated by the exponential component as illustrated in Fig. 1(c) and (d). Thus the central bank penalises higher inflation relative to the target more severely than lower inflation. In similar manner, given the negative value of $\alpha_{y}$, the exponential component dominates the linear component of the loss function whenever $y_{t}$ is less than zero, while the opposite is true for output values greater than zero as illustrated in Fig. 1(e) and (f). Thus, the central bank weighs output contraction relative to the potential level more heavily than output expansions of the same level.

Whenever $\beta_{\pi}$ and $\beta_{y}$ are greater than one, the central bank's preferences are zone-like. this feature was introduced by Orphanides and Wieland (2000). Within the target zones, the central bank's marginal loss is zero. Whenever $\beta_{\pi}$ and $\beta_{y}$ are even, the inflation and output targets are symmetric so that the loss from inflation and output outside the targets are symmetric. Both the inflation and output target zone and the loss from inflation and output outside the target zone are asymmetric whenever $\beta_{\pi}$ and $\beta_{y}$ are odd. Higher values of $\beta_{\pi}$ and $\beta_{y}$ widen the target zone. The responses to inflation and output gaps may be different so that $\beta_{\pi}$ and $\beta_{y}$ may not be equal.

The shape of the linex specification depends on the signs of $\alpha_{\pi}$ and $\alpha_{y}$ such that if the central bank weigh deflation more severely than inflation, then $\alpha_{\pi}$ would be negative. $\alpha_{y}$ can also be positive in which case the central bank is averse to output contractions than expansions. Thus under asymmetric setting, the central bank is concerned about the magnitudes as well as the signs whereas under the symmetric setting, the only concern is the magnitude of deviations of target variables from their reference values. For a detailed discussion on all the possible configurations of the loss function, see Boinet and Martin (2008). 
(a) $\alpha_{\pi ; y} \rightarrow 0 ; \beta_{\pi ; y}=1$

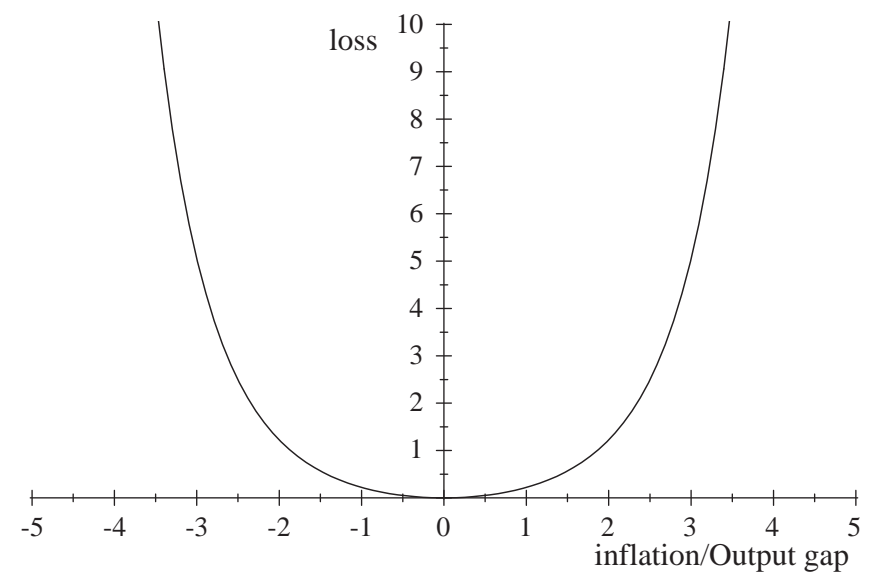

(c) $\alpha_{\pi}>0 ; \beta_{\pi}=1$

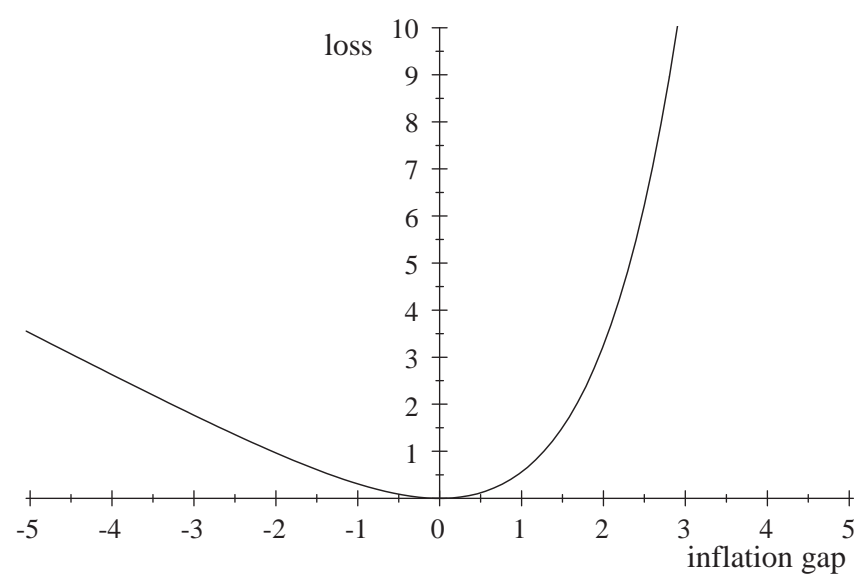

(e) $\alpha_{y}<0 ; \beta_{y}=1$

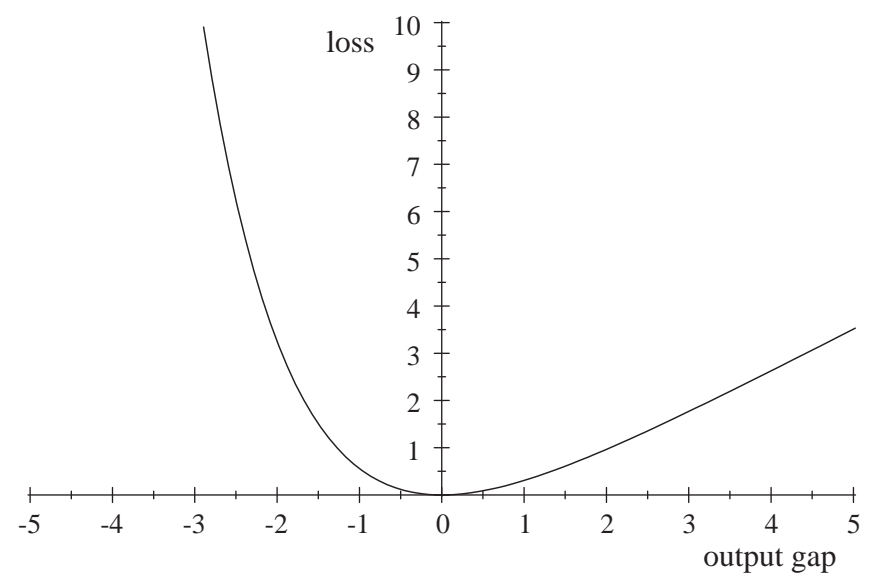

(b) $\alpha_{\pi ; y} \rightarrow 0 ; \beta_{\pi ; y}=2,3,4, \ldots$

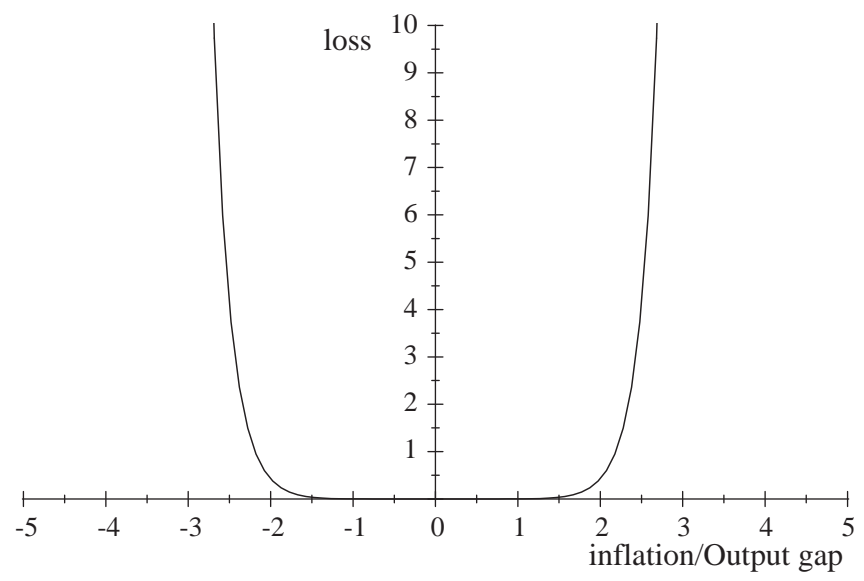

(d) $\alpha_{\pi}>0 ; \beta_{\pi}=3,5,7, \ldots$

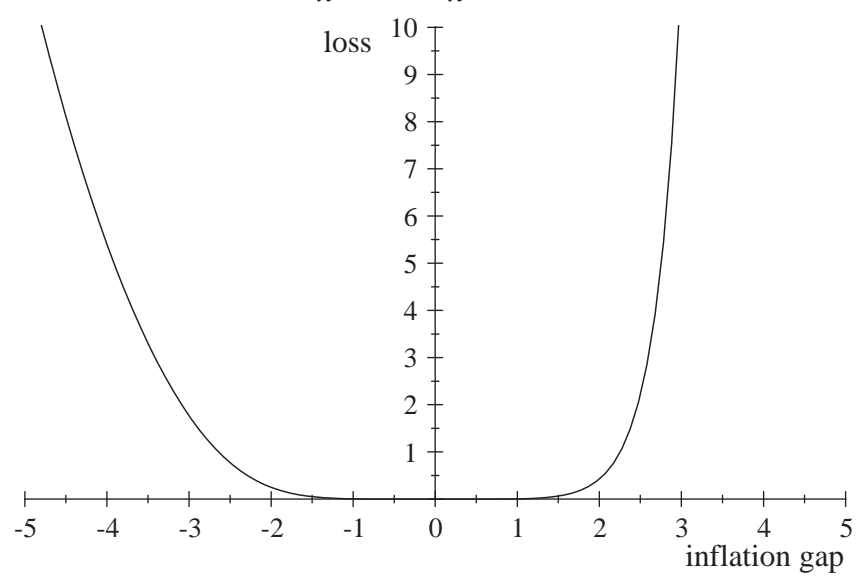

(f) $\alpha_{y}<0 ; \beta_{y}=3,5,7, \ldots$

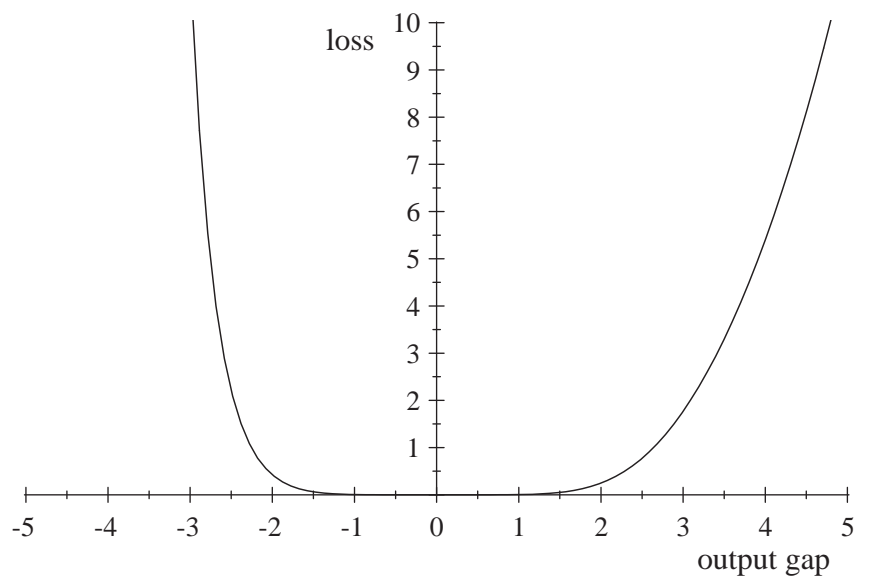

Note: The figure illustrates the preferences over inflation and output embodied by the loss function assuming that monetary authorities have deflationary bias and dislike output contractions

Fig. 1. The loss functions.

\subsection{Structure of the economy}

The framework for the evolution of monetary policy is the New Keynesian sticky price forward looking model of the business cycle. The model is derived in Yun (1996) and Woodford (2003). The economy is represented by a two equation system comprising the aggregate demand and aggregate supply (Phillip's curve) functions.
The aggregate demand is a log-linearised version of the standard Euler equation for consumption combined with the relevant market clearing condition:

$y_{t}=E_{t} y_{t+1}-\varphi\left(i_{t}-E_{t} \pi_{t+1}\right)+\varepsilon_{t}^{d}$ 
where $y_{t}$ is the output gap, $i_{t}$ is the nominal interest rate, $\pi_{t}$ is the inflation rate, while $\varphi>0$ is the coefficient and $\varepsilon_{t}^{d}$ is a demand shock. The aggregate supply curve incorporates consumption smoothing into the aggregate demand formulation where the output gap increases with its future value, while it decreases with the real interest rate $i_{t}-E_{t} \pi_{t+1}$ (Clarida et al., 1999). The aggregate supply (Phillips curve) captures, in a log-linearised manner, the staggered feature of the Calvo type contract:

$\pi_{t}=\theta E_{t} \pi_{t+1}+k y_{t}+\varepsilon_{t}^{s}$

where $\theta>0$ and $k>0$ are the coefficients, while $\varepsilon_{t}^{s}$ is the i.i.d supply shock.

\subsection{Optimal monetary policy}

The central bank chooses monetary policy rates under discretion and the per period instrument $i_{t}$ is chosen to minimise the following objective function:

$$
\begin{aligned}
& E_{t-1}\left(\frac{e^{\alpha_{\pi}\left(\pi_{t}-\pi^{*}\right)^{\beta_{\pi}}}-\alpha_{\pi}\left(\pi_{t}-\pi^{*}\right)^{\beta_{\pi}}-1}{\beta_{\pi} \alpha_{\pi}^{2}}\right) \\
& +\lambda E_{t-1}\left(\frac{e^{\alpha_{y}\left(y_{t}\right)^{\beta_{y}}}-\alpha_{y}\left(y_{t}\right)^{\beta_{y}}-1}{\beta_{y} \alpha_{y}^{2}}\right)+\frac{\mu}{2}\left(i_{t}-i^{*}\right)^{2}+F_{t}
\end{aligned}
$$

Subject to $y_{t}=-\varphi i_{t}+g_{t}$ and $\pi_{t}=k y_{t}+f_{t}$ where $F_{t} \equiv E_{t-1} \sum_{\tau=0}^{\infty} \delta^{\tau} L_{t+\tau}$, $g_{t} \equiv E_{t} y_{t+1}+\varphi E_{t} \pi_{t+1}+\varepsilon_{t}^{d}$ and $f_{t}=\theta E_{t} \pi_{t+1}+\varepsilon_{t}^{s}$. The central bank cannot directly manipulate expectation. As a result, $F_{t}, g_{t}$ and $f_{t}$ are taken as given.

\subsection{Central bank's reaction function}

The reaction function according to which the central bank chooses monetary policy rates in response to developments in the economy is achieved by solving the central bank's optimisation problem above. This translates into the following first order condition that describes the central bank's optimal monetary policy rule.

$\delta E_{t-1} f^{\prime}\left(\pi_{t+1}-\pi^{*}\right) \frac{\partial \pi_{t+1} \partial y_{t+1}}{\partial y_{t+1} \partial i_{t}}+\delta E_{t-1} f^{\prime}\left(y_{t+1}\right) \frac{\partial y_{t+1}}{\partial i_{t}}+\mu\left(i_{t}-i^{*}\right)=0$

where $f\left(x_{t} ; \alpha, \beta\right)=\left(\frac{e^{\alpha x_{t}^{\beta}}-\alpha x_{t}^{\beta}-1}{\beta \alpha^{2}}\right)$ and $f^{\prime}($.$) is the first derivative of$ this function. The parameter $\alpha$ and the exponential function determine the asymmetric response of monetary policy rates to the deviation of target variables from their reference values, while $\beta$ captures the zone-like properties.

Solving Eq. (6) achieves the reduced form of the central bank's reaction function

$\hat{i}_{t}=i^{*}+\omega_{\pi} E_{t-1} f^{\prime}\left(\pi_{t+1}-\pi_{t}^{*}\right)\left(\pi_{t+1}-\pi_{t}^{*}\right)+\omega_{y} E_{t-1} f^{\prime}\left(y_{t+1}\right)\left(y_{t+1}\right)$

where $\hat{i}$ is the optimal interest rate, $\omega_{\pi}=\left(\frac{k \varphi \delta}{\mu}\right)$ and $\omega_{y}=\left(\frac{\lambda \varphi \delta}{\mu}\right)$ are convolutions of parameters representing the central bank's preferences and the structure of the economy and $f^{\prime}\left(x_{t} ; \alpha, \beta\right)=$ $x_{t}^{\beta-1}\left(\frac{e^{\alpha x_{t}^{\beta}}-1}{\alpha}\right)$. The weight on inflation is given by $\omega_{\pi} E_{t-1} f^{\prime}\left(\pi_{t+1}\right.$ $\left.\pi_{t}^{*}\right)$ while the weight on output stabilisation is $\omega_{y} E_{t-1} f^{\prime}\left(y_{t+1}\right)$.

As a special case, the central bank's reaction function above embodies the linear form whenever $\alpha_{\pi}$ and $\alpha_{y}$ approach zero. Using L'Hopital's rule on Eq. (7) as $\alpha_{\pi}$ and $\alpha_{y}$ approach zero and $\beta_{\pi}$ and $\beta_{y}$ approach one, $f^{\prime}($.) tends to unity and the central bank's monetary policy rule generalises to a linear Taylor rule (Taylor, 1993)

$\hat{i}_{t}=i^{*}+\omega_{\pi} E_{t-1}\left(\pi_{t+1}-\pi_{t}\right)+\omega_{y} E_{t-1}\left(y_{t+1}\right)$

The monetary authorities have linex preferences whenever $\beta_{\pi}$ and $\beta_{y}$ are equal to one. This monetary reaction function is similar to those in Nobay and Peel (2003), Ruge-Murcia (2003) and Surico (2007a,b).

The monetary policy reaction function generalise to a linear Taylor rule whenever $\alpha_{\pi}$ and $\alpha_{y}$ approach zero, while it is symmetric whenever $\beta_{\pi}$ and $\beta_{y}$ are greater than one as illustrated in Fig. 2(a) and (b), respectively. The monetary policy reaction function reveals asymmetries to inflation and output whenever $\alpha_{\pi}$ and $\alpha_{y}$ are greater than zero. Assuming that the monetary authority dislikes high inflation, whenever $\alpha_{\pi}$ is greater than zero, monetary authorities are more aggressive when inflation overshoots the target but are less responsive when inflation undershoots the target as shown in Fig. 2 (c) and (d). Further, assuming that monetary authorities are averse to output contractions, as shown in Fig. 2(e) and (f), the asymmetry is reversed whenever $\alpha_{y}$ is less than zero so that monetary authorities are more aggressive when output undershoots the target and relatively passive when it overshoots the target.

Whenever $\beta_{\pi}$ and $\beta_{y}$ are even, the monetary policy reaction function exhibits zone-like preferences similar to that proposed by Orphanides and Wieland (2000). In this case, monetary authorities are passive or do not respond to fluctuations in inflation and output inside the zone. However, the monetary authorities' reaction becomes increasingly aggressive whenever inflation and output moves outside this zone. Their reaction outside the zone is symmetric and increasingly aggressive for the larger values of $\alpha_{\pi}$ and $\alpha_{y}$. Whenever $\beta_{\pi}$ and $\beta_{y}$ are odd, the monetary policy reaction function is asymmetric and exhibits zone-like preferences' similar to that proposed by Boinet and Martin (2008). Similar to the previous case, monetary authorities are passive or do not respond to fluctuations in inflation and output inside the zone. Assuming that monetary authorities' dislike high inflation and output contractions, their response to inflation is somewhat passive when inflation moves below the target zone but becomes increasingly aggressive when inflation moves above the target zone and the response is also aggressive when output undershoots the target zone but less so when it overshoots it.

Thus it is apparent from the preceding discussion that the monetary policy reaction function is flexible in that it can embody linearities and nonlinearities, symmetries and asymmetries as well as zone-like responses to inflation and output depending on the assumptions concerning the monetary authorities' preferences. As a result, determining which specification best fits the data allows the evaluation of the monetary authorities' preferences', which adequately capture the key features in monetary policy conduct.

\subsection{Empirical model}

Estimating the central bank's reaction function in Eq. (7) to test the statistical significance of the parameters amounts to testing linearity against a nonlinear model. To overcome this problem, the central bank's reaction function is linearised to eliminate the expectation terms by approximating Eq. (7) using a first order Taylor series expansion when $\alpha_{\pi}$ and $\alpha_{y}$ tend to zero. Replacing the 
(a) $\alpha_{\pi ; y} \rightarrow 0 ; \beta_{\pi ; y}=1$

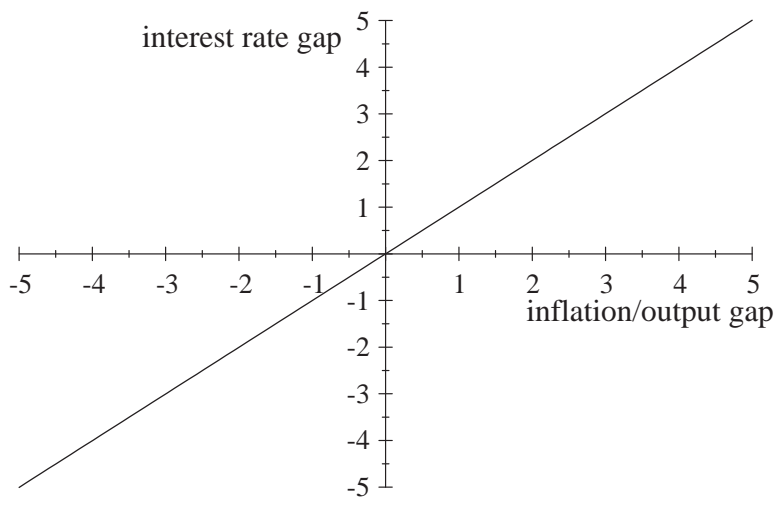

(c) $\alpha_{\pi}>0 ; \beta_{\pi}=1$

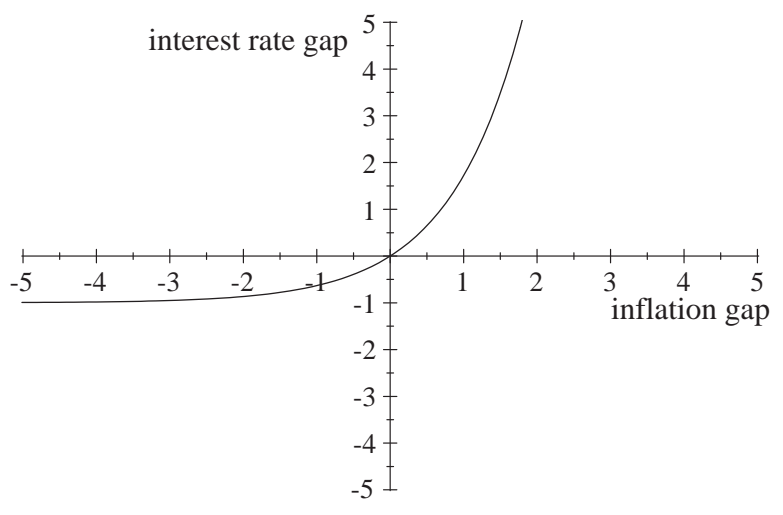

(e) $\alpha_{y}<0 ; \beta_{y}=1$

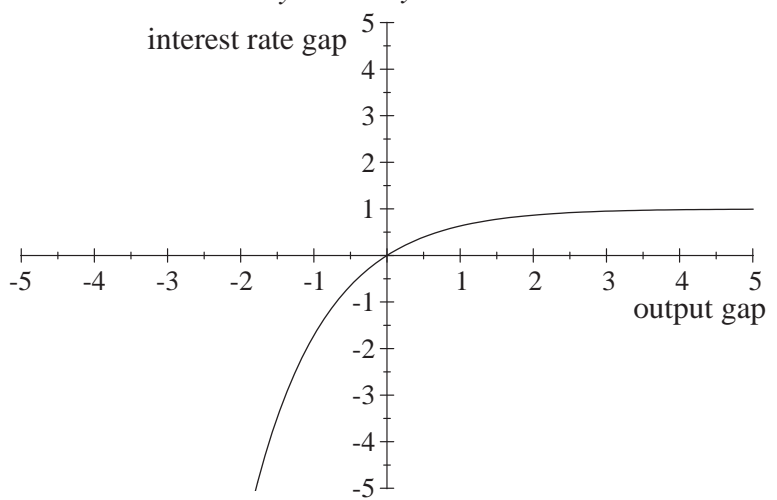

(b) $\alpha_{\pi ; y} \neq 0 ; \beta_{\pi ; y}=2,4,6, \ldots$

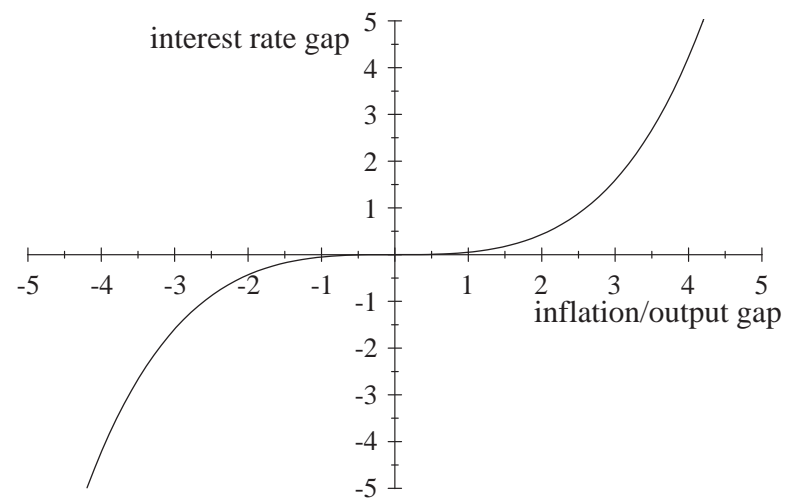

(d) $\alpha_{\pi}>0 ; \beta_{\pi}=3,5,7, \ldots$

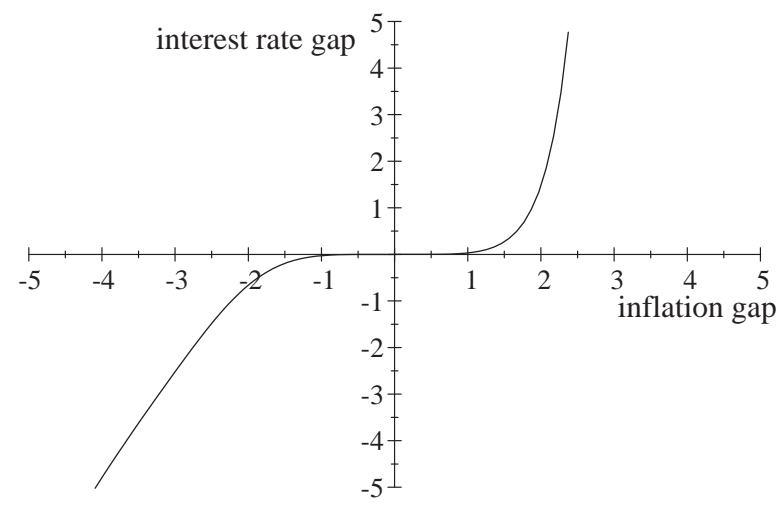

(f) $\alpha_{y}<0 ; \beta_{y}=3,5,7, \ldots$

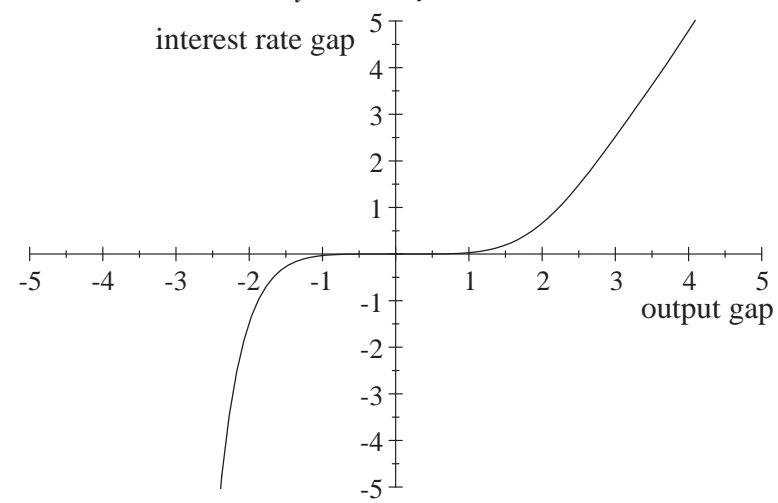

Note: The figure illustrates the gap between the steady-state and equilibrium interest rates calculated using equation [7] assuming that monetary authorities dislike inflation and output contractions.

Fig. 2. Optimal monetary policy rules.

expectations with realised values, the reduced form of central bank's reaction function now becomes:

$$
\begin{aligned}
\hat{i}_{t}= & i^{*}+\omega_{\pi}\left(\pi_{t+1}-\pi^{*}\right)^{2 \beta_{\pi}-1}\left(1+\frac{\alpha_{\pi}}{2}\left(\pi_{t+1}-\pi^{*}\right)^{\beta_{\pi}}\right) \\
& +\omega_{y}\left(y_{t+1}\right)^{2 \beta_{y}-1}\left(1+\frac{\alpha_{y}}{2}\left(y_{t+1}\right)^{\beta_{y}}\right)
\end{aligned}
$$

When $\beta_{\pi}$ and $\beta_{y}$ approach 1 , the monetary authorities have linex preferences. The monetary policy reaction function generalises to a linear Taylor rule when $\alpha_{\pi}$ and $\alpha_{y}$ approach zero. Adding a partial adjustment mechanism $i_{t}=\rho(L) i_{t-1}+(1-\rho(L)) \hat{\imath}_{t}$ to allow for interest rate persistence as in Clarida et al. (1999) achieves the following reduced form of central bank's reaction function:

$i_{t}=\rho(L) i_{t-1}+(1-\rho(L))\left(\begin{array}{l}\omega_{0}+\omega_{\pi}\left(\pi_{t+1}-\pi^{*}\right)^{2 \beta_{\pi}-1}\left(1+\frac{\alpha_{\pi}}{2}\left(\pi_{t+1}-\pi^{*}\right)^{\beta_{\pi}}\right) \\ +\omega_{y}\left(y_{t+1}\right)^{2 \beta_{y}-1}\left(1+\frac{\alpha_{y}}{2}\left(y_{t+1}\right)^{\beta_{y}}\right)\end{array}\right)+\varepsilon_{t}$ 
Where $\varepsilon_{t}$ is the residual of the Taylor's series expansion defined as:

$$
\begin{array}{r}
\varepsilon_{t}=-\omega_{\pi}(1-\rho(L))\left(\begin{array}{c}
\left(\left(\pi_{t+1}-\pi^{*}\right)^{2 \beta_{\pi}-1}-E_{t-1}\left(\pi_{t+1}-\pi^{*}\right)^{2 \beta_{\pi}-1}\right) \\
+\frac{\alpha_{\pi}}{2}\left(\left(\pi_{t+1}-\pi^{*}\right)^{3 \beta_{\pi}-1}-E_{t-1}\left(\pi_{t+1}-\pi^{*}\right)^{3 \beta \beta_{\pi}-1}\right)
\end{array}\right) \\
-\omega_{y}(1-\rho(L))\left(\begin{array}{c}
\left(\left(y_{t+1}\right)^{2 \beta_{y}-1}-E_{t-1}\left(y_{t+1}\right)^{2 \beta_{y}-1}\right) \\
+\frac{\alpha_{y}}{2}\left(\left(y_{t+1}\right)^{3 \beta_{y}-1}-E_{t-1}\left(y_{t+1}\right)^{3 \beta_{y}-1}\right)
\end{array}\right)
\end{array}
$$

\section{Data description}

Monthly data for South Africa is used for the analysis. The data spans the period from January 2000 to December 2008. The three month treasury bill rate is used to measure the rate of interest. We prefer using this interest rate rather than the key policy rate, the repo rate given that it contains more variation. Inflation gap is measured by the difference between the annual change in consumer price index and 4.5, which is the mid-point of the inflation target in South Africa. Output gap is measured by the difference between (in logarithms) coincident business cycle indicator and its Hodrick and Prescott (1997) trend. The instrument set includes the lags of the independent variables, the long term government bond yield, annual change in M3 and the index of financial conditions gap. All the data is sourced from the South African Reserve Bank database.

To tackle the end-point problem in calculating the HP trend (see Mise et al., 2005a,b), we applied an autoregressive $(\operatorname{AR}(n))$ model (with $n$ set at 4 to eliminate serial correlation) to the output measure. The AR model was used to forecast twelve additional months that were then added to the series before applying the HP filter. The main variables are depicted in Fig. 3. The inflation rate is showing a persistent increase towards the end of the sample together with an accompanying increase in interest rate. The output gap is showing a severe downturn by the end of 2008 .

\section{Empirical results}

The orthogonality conditions in the central bank's reaction function allow the use of Generalised Method of Moments (GMM) in estimation. Eq. (10) is estimated using a mixture of integer values of $\beta_{\pi}$ and $\beta_{y}$ when $\alpha_{\pi}$ and $\alpha_{y}$ approach zero and also when $\alpha_{\pi}$ and $\alpha_{y}$ are not equal to zero. The optimal monetary policy reaction functions are estimated in a forward looking manner with a preferred specification that allows a lead structure of six on inflation

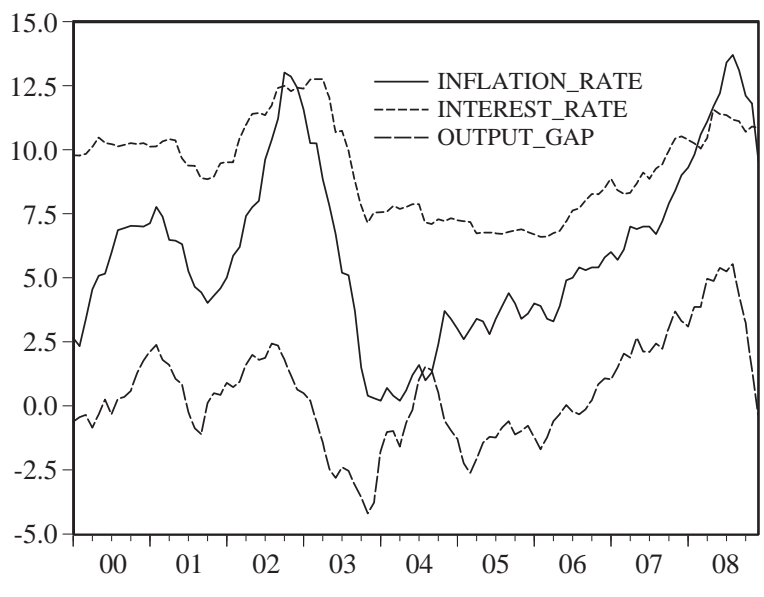

Fig. 3. Evolution of the main variables. gap and one on the output gap. The optimal monetary policy rule is achieved by selecting the model with the lowest standard error among all the alternatives under the different assumptions for inflation and output. As discussed above, the inflation and output gaps can be assumed to be linear, asymmetric, zone symmetric and zone asymmetric.

Table 1 shows the standard errors for all the estimated models under different assumptions for inflation and output. Among the alternatives, the model with a symmetric zone inflation gap and an asymmetric output gap is the preferred model with the lowest standard error. This implies that the monetary authorities react in a passive manner when inflation is within the target band and become increasingly aggressive when it deviates from the target band where they react with the same level of aggressiveness regardless whether inflation overshoots or undershoots the inflation target band. In addition, the monetary authorities react differently to negative and positive deviations of output from the potential.

The estimated results for the preferred model with a symmetric zone inflation gap and an asymmetric output gap are presented in Table 2 together with the estimated results for the linear Taylor rule, which is a benchmark for the estimated monetary policy reaction functions. To determine the validity of the set of instruments, the Hansen's J-test is carried out under the null hypothesis that the over-identifying restrictions are satisfied. The null hypothesis is accepted for both the preferred model and the benchmark model. However, the preferred model provides slightly better fit to the data compared with the benchmark model and relatively better model diagnostics. The diagnostic tests show no serious misspecification in Table 2 except for a heteroscedasticity issue for the linear model. We implement two statistical tests to support the nonlinear results. The estimates of the linear model fail a Chow test of parameter stability. ${ }^{3}$ This failure implies that the Taylor rule is an inadequate model of monetary policy and provides further support for our model. The estimates of the preferred model with a symmetric zone response to inflation and a nonlinear response to output do not suffer from parameter instability. The Ramsey RESET test further concludes that the general specification of the linear regression model is not appropriate.

The results for both models show statistically significant coefficients for inflation gap and the output gap. The optimal monetary policy preferences implied by these estimates are illustrated in Fig. 4. The preferred model shows a negligible response to inflation when it deviates by about $0.5 \%$ from the inflation target mid-point of $4.5 \%$. The results show that the monetary authorities increase the nominal interest rates by $0.4 \%$ when inflation hits the upper threshold of the inflation target band so that the desired nominal interest rate is at $8.7 \%$ compared with the equilibrium interest rate of $8.4 \%$. When inflation deviates by $1 \%$ outside the upper bound of the inflation target, the monetary authorities increase the nominal interest rates by $2.9 \%$ so that the desired nominal interest rate is $11.4 \%$.

The benchmark model implies a constant response of interest rates to changes in inflation regardless of its deviation from the target. The results show that the monetary authorities move interest rates by $0.8 \%$ when inflation deviates from the inflation target range mid-point of $4.5 \%$ by $1 \%$. The response of nominal interest rates to changes in inflation implied by the benchmark model is stronger than that which is implied by the preferred model when inflation is between 1.6 and $7.4 \%$.

With regard to output, the estimated optimal monetary policy rule for the preferred model shows that the monetary authorities cut nominal interest rates by $1 \%$ when output undershoots the potential

\footnotetext{
${ }^{3}$ This conclusion is robust to using other dates for the break point of the stability test.
} 
Table 1

Standard errors for values of $\beta_{\pi}$ and $\beta_{y}$

\begin{tabular}{|c|c|c|c|c|}
\hline & $\begin{array}{l}\text { Linear } \\
\alpha_{\pi} \rightarrow 0 ; \beta_{\pi}=1\end{array}$ & $\begin{array}{l}\text { Asymmetric } \\
\alpha_{\pi} \neq 0 ; \beta_{\pi}=1\end{array}$ & $\begin{array}{l}\text { Symmetric zone } \\
\alpha_{\pi} \neq 0 ; \beta_{\pi}=2\end{array}$ & $\begin{array}{l}\text { Asymmetric zone } \\
\alpha_{\pi} \neq 0 ; \beta_{\pi}=3\end{array}$ \\
\hline Linear $\alpha_{y} \rightarrow 0 ; \beta_{y}=1$ & 0.320672 & 0.3117229 & 0.321301 & 0.325426 \\
\hline Asymmetric $\alpha_{y} \neq 0 ; \beta_{y}=1$ & 0.310730 & 0.312119 & 0.304125 & 0.318219 \\
\hline Symmetric zone $\alpha_{y} \neq 0 ; \beta_{y}=2$ & 0.326905 & 0.322175 & 0.322711 & 0.322974 \\
\hline Asymmetric zone $\alpha_{y} \neq 0 ; \beta_{y}=3$ & 0.321068 & 0.317063 & 0.318193 & 0.319374 \\
\hline
\end{tabular}

by $0.8 \%$. The negative coefficient on the parameter that governs asymmetry implies that monetary authorities' are more aggressive when output falls below that when it overshoots the potential. This implies that monetary authorities' preferences' are biased towards output expansions in that they weigh negative deviations of output more heavily than output expansions. The results for the benchmark model show a constant response to output contractions and expansions as discussed above. The estimated results show that the monetary authorities move the nominal interest rates by $0.4 \%$ when output deviates from the desired level by $1 \%$. The preferred model implies a stronger reaction to output fluctuations compared with the benchmark model whenever output is below its potential.

The results for the benchmark monetary policy rule show lower coefficients compared to the recommended size of the coefficients for the Taylor rule. Thus the estimated benchmark model does not adhere to the Taylor principle that the monetary authorities should move interest rates by more than one to one. This is particularly the case with regard to inflation whereas it is not much the case concerning the output gap. The type of model that is implied by the preferred model has not been estimated for South Africa. As a result, there are no studies to compare the results that are obtained in this analysis with. However, our paper draws from Boinet and Martin (2008) who estimate the optimal monetary policy reaction function for the UK. They find similar results in terms of symmetric zone inflation but linearity in terms of the output gap. The estimated coefficients in Boinet and Martin (2008) for the monetary authorities' response to inflation in the UK are larger than the estimated coefficients for the case of South Africa. One of the possible reasons for this is because the inflation target for the UK is $2.5 \%$, which is much lower than that of South Africa. This calls for a more aggressive policy response on the part of the monetary authorities in the UK.

\section{Conclusion}

This paper estimates the monetary authorities' response to deviations of inflation and output from their target values using an empirical framework that allows central bank's policy preferences to be zone-like and asymmetric. Of particular interest is whether the monetary authorities' preferences are such that they behave differently to deviations in inflation and output when they overshoot or are below their target values and/or when inflation is within or outside the target range. Monthly data for South Africa spanning the period since inflation targeting framework was adopted is used in the analysis. The optimal monetary policy response functions are estimated in a forward looking manner for linearities and nonlinearities, symmetries and asymmetries as well as zone-like responses to inflation and output gaps.

The results show that the monetary authorities react in a passive manner when inflation is about $0.5 \%$ from the inflation target midpoint of $4.5 \%$ and become increasingly aggressive when it deviates from the target band. The monetary authorities increase the nominal interest rates by $0.4 \%$ when inflation hits the upper threshold of the inflation target band and they increase the nominal interest rates by $2.9 \%$ when inflation deviates by $1 \%$ outside the upper bound of the inflation target. The results also show that the monetary authorities react with the same level of aggressiveness regardless whether inflation overshoots or undershoots the inflation target band. With regard to output, the monetary authorities cut nominal interest rates by $1 \%$ when output undershoots the potential by $0.8 \%$ and they react

Table 2

GMM estimates for the nonlinear monetary policy rules.

\begin{tabular}{|c|c|c|c|c|}
\hline & \multicolumn{2}{|c|}{$\begin{array}{l}\text { Linear inflation and linear output gap } \\
\alpha_{\pi} \rightarrow 0 ; \alpha_{y} \rightarrow 0 ; \beta_{\pi}=1 ; \beta_{y}=1\end{array}$} & \multicolumn{2}{|c|}{$\begin{array}{l}\text { Zone symmetric inflation and asymmetric output } \\
\text { gap } \alpha_{\pi} \neq 0 ; \alpha_{y} \neq 0 ; \beta_{\pi}=2 ; \beta_{y}=1\end{array}$} \\
\hline & Coefficient & Std error & Coefficient & Std error \\
\hline$\rho$ & $0.938862^{*}$ & 0.007366 & $0.952855^{*}$ & 0.005851 \\
\hline$\omega_{0}$ & $7.827308^{*}$ & 0.194708 & $8.392031^{*}$ & 0.289229 \\
\hline$\omega_{\pi}$ & $0.804001^{*}$ & 0.118355 & $0.108174^{*}$ & 0.015844 \\
\hline$\alpha_{\pi}$ & & & $-0.025877^{*}$ & 0.000660 \\
\hline$\omega_{y}$ & $0.398205^{*}$ & 0.164511 & $0.779056^{*}$ & 0.181125 \\
\hline$\alpha_{y}$ & & & $-0.805241^{*}$ & 0.158182 \\
\hline$\overline{\mathrm{R}}^{2}$ & 0.970032 & & 0.973045 & \\
\hline Std. Error & 0.320672 & & 0.304125 & \\
\hline$J$-statistic & 0.984520 & & 0.989988 & \\
\hline$F_{a r}$ & $1.37[0.24]$ & & $0.71[0.62]$ & \\
\hline$F_{\text {arch }}$ & $3.02[0.01]$ & & $1.10[0.37]$ & \\
\hline Jaque Bera & $1.81[0.40]$ & & $1.93[0.38]$ & \\
\hline Chow F-stat & $2.87[0.03]$ & & $1.16[0.34]$ & \\
\hline RESET test & $26.38[0.00]$ & & & \\
\hline
\end{tabular}

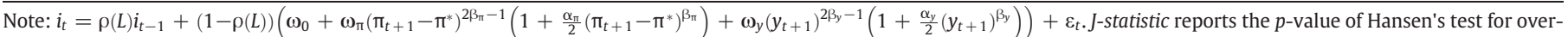

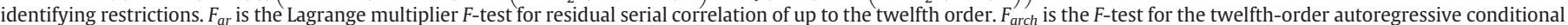

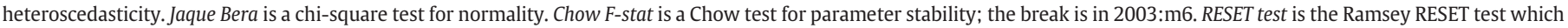
is a chi-square test for general specification of linear regression model and includes up to the cubic terms of the regressors.

* Denotes statistical significance at 5\% level. 


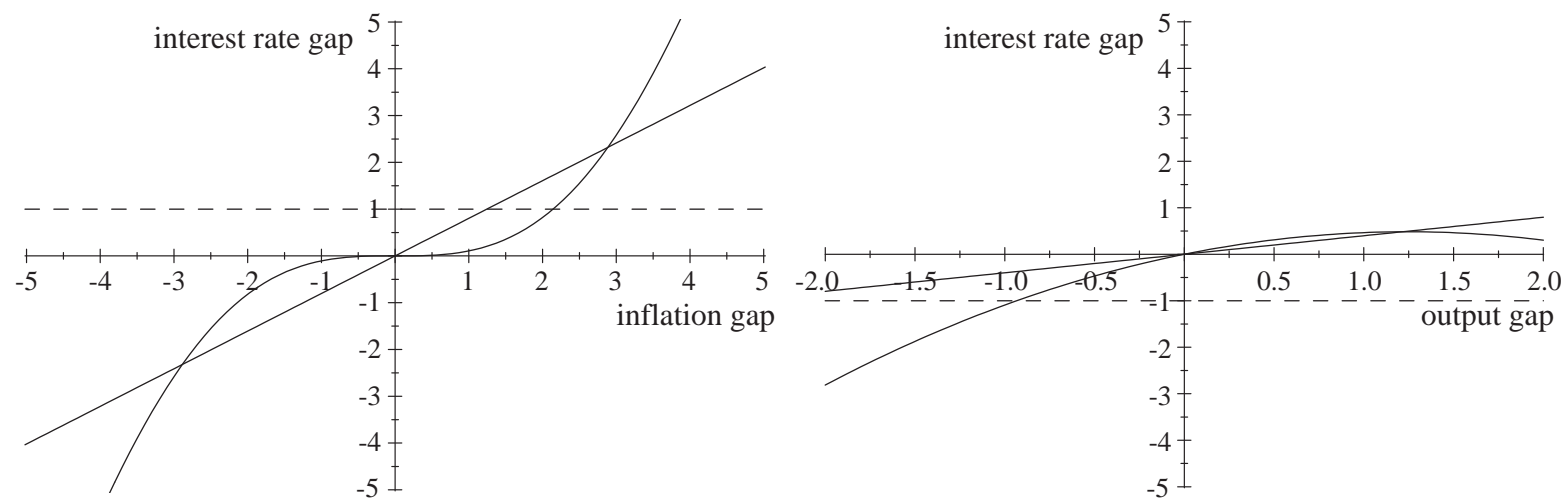

Note: the figures are obtained by substituting the estimates of inflation and output in equation [7] for the both the linear and the non-linear monetary policy rules

Fig. 4. Estimated optimal monetary policy responses to inflation and output.

differently to negative and positive deviations of output from the potential showing that they are more aggressive when output falls below that when it overshoots the potential. Future research can extend this analysis by evaluating the monetary authorities' reaction to other macroeconomic and financial variables such as asset prices and exchange rates.

\section{Acknowledgments}

We thank an anonymous referee for his helpful comments and seminar participants at the University of Pretoria, participants at the African Econometric Society conference and the Economic Society of South Africa conference for valuable feedback.

\section{References}

Boinet, V., Martin, C., 2008. Targets, zones and asymmetries: a flexible nonlinear model of recent UK monetary policy. Oxford Economic Papers 60 (3), 423-439.

Clarida, R., Gali, J., Gentler, M., 1999. The science of Monetary Policy: A New Keynesian Perspective. : NBER Working Paper, 7147. National Bureau of Economic Research, Massachusetts.

Clarida, R., Galí, J., Gertler, M., 2000. Monetary Policy Rules and Macroeconomic Stability: Evidence and Some Theory. Quarterly Journal of Economics 115, 147-180.

Cukierman, A., Gerlach, S., 2003. The Inflation Bias Revisited: Theory and Some International Evidence: CEPR Discussion Papers, 3761.

Dolado, J.J., Maria-Dolores, R., Naveira, M., 2004. Nonlinear monetary policy rules: some new evidence for the U.S. Studies in Nonlinear Dynamics and Econometrics 8 (3), 1155-1155.

Dolado, J.J., Maria-Dolores, R., Naveira, M., 2005. Are monetary-policy reaction functions asymmetric?: The role of nonlinearity in the Phillips curve. European Economic Review 49 (2), 485-503.
Hodrick, R.J., Prescott, E.C., 1997. Post-war U.S. business cycles: an empirical investigation. Journal of Money, Credit and Banking 29 (1), 1-16 February.

Mise, E., Kim, T.H., Newbold, P., 2005a. On the sub-optimality of the Hodrick-Prescott Filter. Journal of Macroeconomics 27, 53-67.

Mise, E., Kim, T.H., Newbold, P., 2005b. Correction of the Distortionary end-effect of the Hodrick-Prescott Filter: Application. Mimeo. Available from: http://www.le.ac.uk/ economics/staff/em92.html.

Mishkin, F.S., Schmidt-Hebbel, K., 2001. One Decade of Inflation Targeting in the World: What Do We Know and What Do We Need to Know? : NBER Working Papers, 8397. National Bureau of Economic Research.

Naraidoo, R., Gupta, R., 2008. Modeling Monetary Policy in South Africa: Focus on Inflation targeting Era Using a Simple Learning Rule. : Working paper, 200904. Department of Economics, University of Pretoria.

Nobay, R., Peel, D., 2003. Optimal monetary policy in a model of asymmetric central bank's preferences. Economic Journal 113 (489), 659-665.

Orphanides, A., Wieland, V., 2000. Inflation zone targeting. European Economic Review 44 (7), 1351-1387.

Orphanides, A., Wilcox, D.W., 2002. The opportunistic approach to disinflation. International Finance 5 (1), 47-71.

Ruge-Murcia, F.J., 2003. Inflation targeting under asymmetric preferences. Journal of Money, Credit and Banking 35 (5), 763-785.

Surico, P., 2007a. The monetary policy of the european central bank. Scandinavian Journal of Economics 109 (1), 115-135.

Surico, P., 2007b. The Fed's monetary policy rule and U.S. inflation: the case of asymmetric preferences. Journal of Economic Dynamics and Control 31, 305-324.

Svensson, L.E.O., 1999. Inflation targeting as a monetary policy rule. Journal of Monetary Economics 43 (3), 607-654.

Taylor, J.B., 1993. Discretion versus policy rules in practice. Carnegie-Rochester Conference Series on Public Policy 39 (1), 195-214 December.

Woodford, M., 2003. Interest and Prices: Foundations of a Theory of Monetary Policy. Princeton University Press, New Jersey.

Yun, T., 1996. Nominal price rigidity, money supply endogeneity, and business cycles Journal of Monetary Economics 37 (2-3), 345-370. 